\title{
The Research on Subject Behavioral Risk of Whole Life-cycle Water Conservation Projects
}

\begin{abstract}
In 2011, water conservation projects construction in China entered a stage of rapid growth. In February 2013 three dam safety accidents occurred due to improper participant subject behaviors. Improving security and risk management of water conservation projects is therefore considered as imminent. It is urgent to research the risks of the participant subject behaviors. This article takes each participating subject in the whole life-cycle of water conservation projects as the research object, analyzes the risk behaviors and risk evolution processes, dissects the cause of the risks of the participating subject behaviors on the basis of the theory of risk effect, and puts forward that reinforcing the penalties, improving criminal cost and strengthening the engineering ethics education is an effective way to solve safety problems of the current projects.
\end{abstract}

Keywords: water conservation projects, subject behavior, safety accident, risk effect, engineering ethics

\section{Introduction}

Beginning in 2013, water resources project accidents have frequently happened. On February 2, 2013, a dam failure accident occurred at the Xinjiang Urumqi Lianfeng reservoir, which was storing water without being completed. Also on February 2, 2013, a dam failure happened at the Xinghuo reservoir in Heilongjiang due to lengthy high water levels and excess water storage and improper operation management. On February 15, 2013, the Quting reservoir dam collapsed due to improper subject behavior. This series of accidents reflect a series of problems in the construction of water conservation projects. Studies of the risk management of water conservation projects have

Manuscript received July 22, 2014; accepted October 5, 2014

Hong-yong Liu, Ji Guo $(\bowtie)$, Wei-tao He

School of Civil Engineering and Architecture, Southwest Petroleum University, Xindu, Chengdu 610500, China

Email:1205073056@qq.com mostly focused on the events. However, the major cause for these failures is subject misconduct which is often neglected by researchers both in the literature review and engineering practice.

During the life of the projects, various agents work together and create benefit communities, thus, they will certainly make a profit for themselves and can be tempted by their interests. American scientist Heinrich (1959) developed his famous domino theory of accident causation (domino accident theory) during research on the risk of subject behaviors, that is the basic factors of accidents is unsafe behavior of people implying that management should be responsible for accidents. The findings of the study on the causes of project failures conducted by Cleland (2002) showed that there are 9 belonging to the subject improper behavior of the 19 reasons in his summary. By using the expected benefits, Au and Chan $(2005,2007)$ found that the subject risk behavior patterns and their attitudes are highly correlated. Adams, Bedard and Johnstone (2005) revealed that traditional research of the projects risk management mostly implied an absence of asymmetric information among the subjects which is prevalent. According to this study, Verma and Terpenny (2005) proposed a dynamic project management thinking based on the principal-agent model. Muller and Turner (2005) analyzed the type of contract and agency relationships, as well as their impact on the communication between the projects manager and project owners. Philip and Armando (2009) carried out a study on the multitasking existing in the principal-agent relationship, pointed out that it may result in low efficiency of resource allocation among several projects due to the limitation of proxy energy and risk-taking ability if the proxy is multitasking. In our country, Yang (2003) put forward the concept of risk of projects subjects' behavior for the first time and analyzed the importance of it. Ren, $\mathrm{Wu}, \mathrm{Xu}$ and Zhang (2004) stated that moral hazard and adverse selection induced by information asymmetry is the main reason for project risk in the main body behavior. Based on the viewpoint of subject behavior risk, Wang and Liu (2008) analyzed the low price bidding phenomenon in construction market by using the incomplete information 
game theory. Xiang, Zhang and Zhang (2012) analyzed projects risk subject behavior, established a risk evaluation index system and a comprehensive evaluation model; Xiang, Ren, Zhong and Feng (2007) studied the risk conduction mechanism among project subject behaviors through introducing the theory of asymmetric information engineering to projects risk management research.

From recent research at home and abroad, the research into projects risk of subject behavior is still lacks systematic study that views the life cycle at each stage. In recent years, project risk subjects' behavior has gradually attracted researcher attention. However, in our country, it is still in its initial stage compared to traditional risk research projects. Therefore, the study on subjects' behavior in water conservation projects using the perspective of life cycle is not only of theoretical significance, but also has important practical value.

\section{Analysis of risk factors of the subjects' behavior in water conservation projects in the life cycle}

Participation in water resources project includes owners, surveyors, designers, contractors, supervisors, and managers. The risk of subject behavior in water resource projects refers to the possibility of loss caused by that the participants specific behavior (Yi, 2010). The relationship among major participants involved in the construction of water conservation projects is shown in Figure 1.

There are many subject behavior risk factors in water conservation project accidents during its life cycle. Accordingly, this article analyzes the risk factors of subject behavior which influences larger areas in light of the current circumstances of water conservation project construction in China.

Risk factors caused by contractors: Water conservation construction has fewer construction enterprises because a large number of projects are done in a short time. The lack of ethical consciousness in many construction enterprises and even botanical garden construction is driven by interests that are also present in the water conservation construction industry. These construction companies tender bids to qualify using illegal means to obtain low costs. There are a considerable number of the construction companies involved which leads to intense competition, low quoted prices and vicious competition. After winning the contract, these enterprises cut corners and find subcontractors as a way to seek obtain benefits due to technical, financial and other problems while further increasing security risks.

Risk factors caused by supervisors: supervisors lack professional ethics during engineering construction. They do not take their responsibilities seriously, either. They engage in fraud with the contractors to cheat for benefits despite of the higher risk.

Risk factors caused by owners: this factor mainly focuses on the following aspects. First, there are dangers hidden in every stage of the life-cycle because of the unreasonable planning by the owners. Second, in order to get interests, owners send the incorrect instructions, which interfere with the normal construction and operation of the projects. Finally, driven by economic interests or achievements, owners give orders out of line and make put projects into operation too early and regardless of the safety.

Risk factors caused by managers: managers make irrational decisions to run administration, and some of them tend to make maximum benefit when it comes to the choice of benefits and costs. Presently in our country, as collective decision does not to impose pursue personal responsibilities and purse violators and the cost of crime is low which, when coupled with lack of ethics, the phenomenon of decision-making errors manifests everywhere.

\section{Risk evolution analysis of subject behavior of water conservation projects life-cycle}

Based on the status quo of China's water conservation projects and the above subject behavioral risk factors to the life-cycle of the water conservation projects, an analysis is made of the evolutionary process of the subject behavior for the life-cycle of the water conservation projects, which could lead to safety accidents. It is shown in Figure 2.

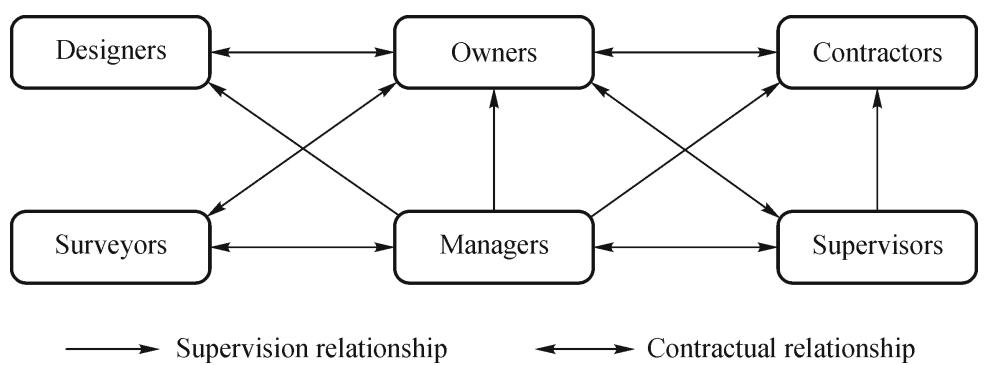

Figure 1. Relationship among major participants in water conservation projects. 


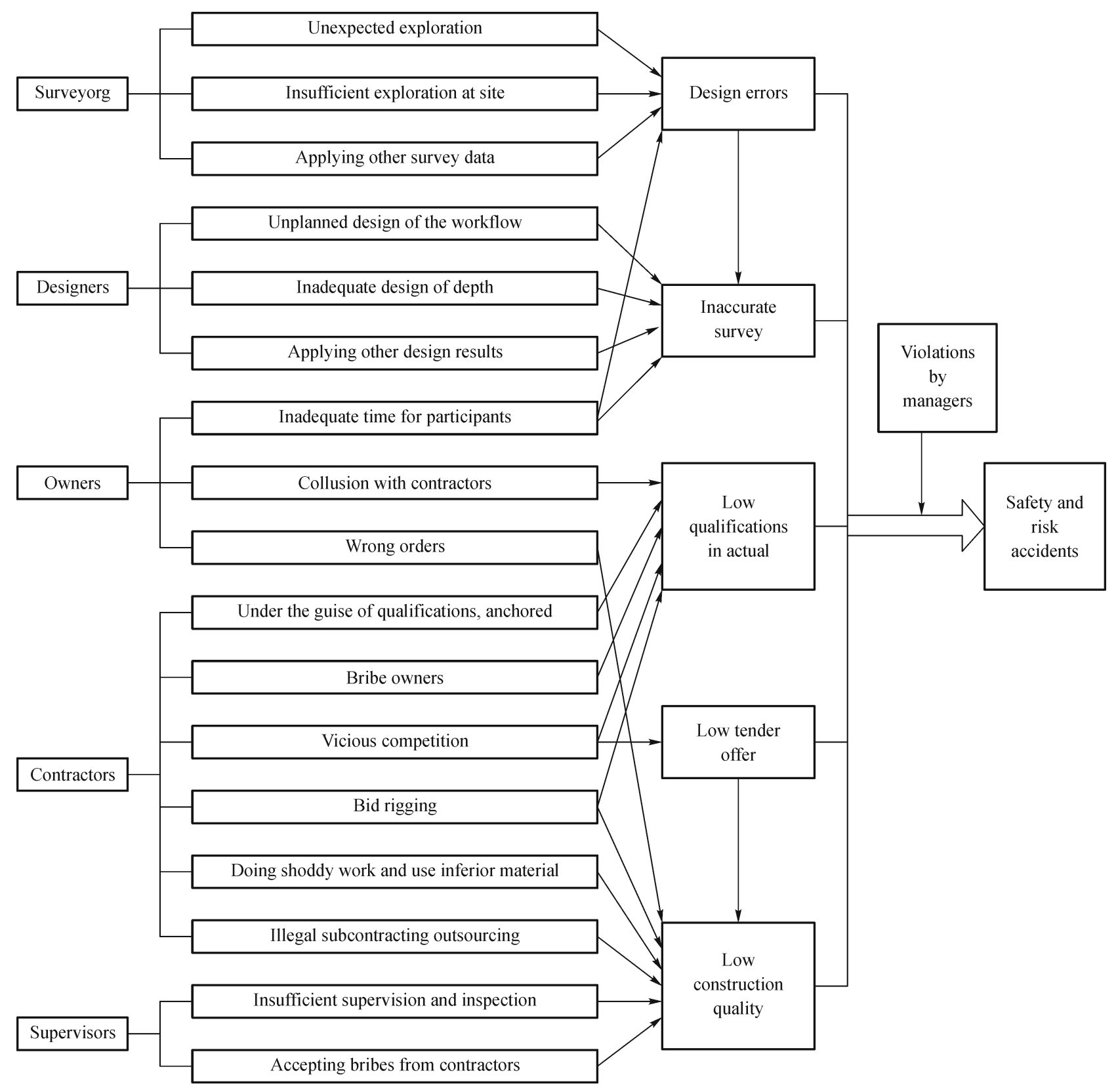

Figure 2. The evolution of subject behavior during water conservation projects life-cycle.

\section{Cause analysis of subjects' behavior risk in water conservation projects in life-cycle}

Risk effect is characteristic of risk events and the internal mechanism of effect (Li \& Shen, 2001) which it embodies when associated with individual motivation and the external environment. Risk effect can be characterized as temptation effect, restraint effect, and balance effect.

Temptation effect refers to a person making a choice for the good of a risk interest leading to risk behavior. Interest risk is a kind of uncertainty benefit or comprehensive benefit. It cannot be determined whether this kind of interest occurs before the results of the risk appeared. It tempts everyone (Yang, 2008).

Restraint effect is an individual's resistance or avoidance to prevent a risk of loss or danger.

On the one hand there is a temptation effect in the risk. On the other hand, there is also a restraining effect of the risk. When the temptation effect and constraint effect are equal, there is a balance of risk effect, called the "balance point". The formative process of the balance point is essentially the weighing process between temptation and constraint conducted by the decision-maker. It is also a process of game of interest and moral. It is shown in Figure 3. 


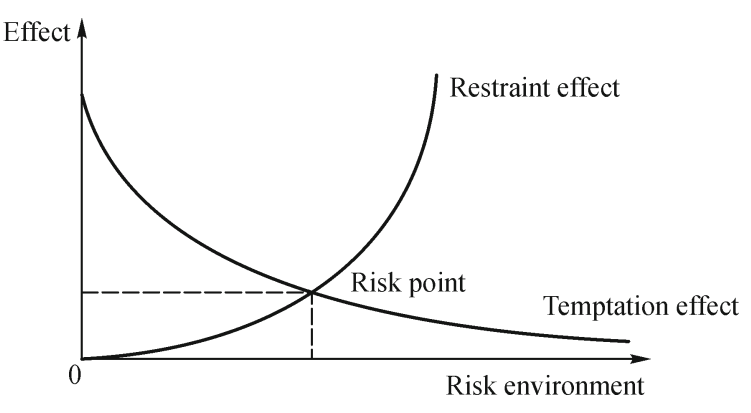

Figure 3. Risk effect balancing.

In China, the root cause of dam accidents is that subjects participating in the projects do things lacking engineering ethics and are drawn to the temptation of their interests. For example: Violating water quality standards, false qualifications, etc. Implementation is at the foundation of the national investment construction projects and has a more complicated approval process and costs are strictly controlled. If engineering construction projects cannot be completed within the prescribed time, project funding is withdrawn. This makes for a tight engineering construction schedule and the time needed for projects survey, design, and construction cannot be guaranteed. Furthermore, water conservation construction projects are exclusively collective decision projects in that there are many participants in the decision-making process. The context of water conservation construction is unclear. Collective decisionmaking responsibilities, imperfect punishment mechanisms, low costs imposed upon individuals involved in collective crimes are ineffective restraints. The owners affected by the performance drive and capital limitation may not provide adequate time to the designers, which generates subject' behavior risks involved in survey and design, and also the contractor and operation management projects.

The risk analysis of subject behavior reflects the current status of China's water conservation projects. With the rapid development of the social economy, people's value orientation distorts behavior due to the low cost imposed upon crime and the tendency that projects participants are driven by adverse selection and moral hazard. This reflects engineering ethics issues. The participants lack ethical consciousness and are unaware that their behavior faces questions characteristic of ethics (Li, 2006). Participants do not have an understanding of their professional and ethical responsibilities. When faced with ethical situations, they make a value judgment deviating from ethics in consideration of various aspects (Wang, 2009). When other values conflict with moral values, the moral values are strongly attracted to subject participants, and the subject participants involved in the temptation opts for a route that takes places personal benefit in precedence over ethical behavior (Khalid \& Al-Rawahy, 2013), leading to the risk, ends in accident.

\section{Prevention countermeasures to subjects' behavior risk in water conservation projects}

The risk of subject behavior is dubious and hard to manage. Behavior risk is always greater than technical risk (Xiang \& Kong, 2010). Therefore, increasing penalties, raising the cost of crime; improving engineering ethics education, improving subject participant ethical consciousness and moral judgment abilities, and strengthening professional ethical responsibilities for engineers is an effective solution. Hence it is necessary to draw lessons from the way of registered engineer examinations are done in United States and add ethical content to the relevant qualification examinations. Meanwhile, it's also necessary to strengthen engineering ethics education for students majoring in engineering, and improve their ethical consciousness and judgment powers.

\section{Conclusions}

The dual background is that the government makes every effort to construct water conservation projects and it is a situation full of "Chinese characteristics". It is imperative to further strengthen the water conservation project management. The roots of the coming risks in water conservation projects are the improper behavior of the subject. It is mainly related to surveyors, designers, owners, contractors, supervisors, operators and managers throughout the project. In the transfer process, the subject behavioral risk continues to increase leading to safety accidents in the end. The study of subject behavioral risk of water resources projects will help prevent the occurrence of the subject behavioral risk from the perspective of the blocking risk. Raising the costs of crime, strengthening engineering ethics education and introducing engineering ethics into the qualification examination process will fundamentally help to prevent misconduct involved in the projects.

\section{References}

Au, M. C. Y., \& Chan, E. H. W. (2005). Attitudes of contractors and employers towards transfer of a time-related risk in construction contracts. Construction Research Congress 2005: Broadening Perspectives-Proceedings of the Congress

Adams, F. G., Bedard, J. C., \& Johnstone, M. (2005). Information asymmetry and competitive bidding in auditing. Economic Inquiry, 43, 417-425

Chan, E. H. W., \& Au, M. C. Y. (2007). Building contractors' behavioral pattern in pricing weather risks. International Journal of Project Management, 25, 615-626

Cleland, D. I., \& Ireland L. R. (2002). Project Manager's Portable Handbook. New York: McGram-Hill 
Heinrich, H. W. (1959). Industrial Accident Prevention. New York: McGram-Hill

Khalid, H., \& Al-Rawahy (2013). Engineering education and sustainable development: the missing link. Procedia: Social and Behavioral Sciences, 102, 392-401

Li, Q., \& Shen, L. (2001). Risk management risk effect behavior strategy and analysis. Theory and Practice of Systems Engineering, 10, 1-8

Li, S. (2006). Analysis of the causes of engineering ethics consciousness. Journal of Beijing Institute of Technology, 8, 93-97

Muller, R., \& Turner, J. R. (2005). The impact of principal-agent relationship and contract type on communication between projects owner and manager. International Journal of Project Management, 23, 398-403

Philip, B., \& Armando, G. (2009). Multitask principal-agent problems: Optimal contracts, fragility and effort misallocation. Journal of Economic Theory, 144, 175-211

Ren, Y. L., Wu, G. S., Xu, J., \& Zhang, Y. (2004). The Economics analysis of the subject participant behavior of the projects. Chongqing University Natural Science, 27, 142-145

Verma, A., \& Terpenny, J. (2005). Dynamic projects management: a principal-agent based approach. Atlanta: IIE Annual Conference and Exposition

Wang, W., \& Liu, D. (2008). The game theory of incomplete information analysis on low price bid phenomenon during the projects construction bidding. Chinese Journal of Management Science, 10, 444448

Wang, Q. (2009). Projects risk ethics and control (Dissertation for the Master's Degree). Chongqing: Chongqing University

Xiang, P. C., Ren, H., Zhong, Y., \& Feng, Y. B. (2007). The game theory analysis on subject behavior of projects based on information asymmetry theory. Journal of Chongqing University (Natural Science Edition), 30(10), 144-151

Xiang, P. C., \& Kong, D. P. (2010). The risk analysis and comprehensive evaluation on the subject behavior of projects. Statistics \& Decisions, 6, 183-185

Xiang, P. C., Zhang, Y., \& Zhang, J. (2012). Researches on conduction mechanism of behavioral risk of principal participant in projects. Construction Economy, 8, 47-50

Yang, B. J. (2003). Several international projects risk management problem worthy of study. Technological Economy, 12, 47-48

Yang, L. (2008). Risk assessment of the subject behavior on highway during the operation (Dissertation for the Master's Degree). Changsha: Changsha University

Yi, S. (2010). The risk assessment and control of subject behavior on highway engineering projects construction (Dissertation for the Master's Degree). Changsha: Changsha University 